\title{
"Um bombeiro pede socorro!": socialização, treinamento e sofrimento na formação do bombeiro militar
}

\section{Fábio Gomes de França* Luziana Ramalho Ribeiro*}

\section{Resumo}

Objetivamos, neste artigo, compreender a relação que se estabelece entre a cultura militarista e processos de socialização baseados no sofrimento na formação do bombeiro militar. Para tanto, tomamos como exemplo paradigmático o caso da morte de um aluno soldado bombeiro militar, ocorrido em 2016 na cidade de Cuiabá, Mato Grosso. Com base em uma pesquisa qualitativa e documental, incluindo levantamento histórico da literatura sobre o tema e da legislação sobre a organização dos bombeiros militares no Brasil, entre outros documentos, analisamos o relatório final do Inquérito Policial Civil (IPC) realizado, o qual apontou a prática de tortura por parte de uma instrutora (uma Tenente) de salvamento aquático. Concluímos que uma pedagogia baseada no sofrimento físico e psíquico encontrada nas Forças Armadas e Polícias Militares também faz parte da formação do bombeiro militar, a qual não deve ter por objetivo os ideais da guerra.

Palavras-chave: bombeiros militares. violência. socialização. cultura militar.

\footnotetext{
* Universidade Federal da Paraíba, João Pessoa, PB, Brasil.
} 


\section{"A fireman cries for help!": socialization, training and suffering in the military firefighter training}

Abstract

This article is aimed at unveiling the relationship between militarist culture and socialization processes based on suffering in the military firefighter training. To that end, we take as a paradigmatic example the case of the death of a military firefighter trainee, occurred in 2016 in the city of Cuiabá, Mato Grosso. Based on qualitative and documentary research, including a historical survey of the literature on the subject and of the legislation on the organization of military firefighters in Brazil, we analyzed the final report of the Civil Police Inquiry (IPC). It pointed out the practice of torture by an instructor (a lieutenant) of aquatic rescue. We conclude through the analysis that a pedagogy based on physical and psychic suffering found in the Armed Forces and Military Police is also part of the military firefighter training that should not be guided by ideals of war.

Keywords: military firefighters. violence. socialization. military culture.

\section{Introdução}

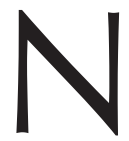

o meio acadêmico, pesquisas sobre a formação profissional dos Corpos de Bombeiros Militares (CBMs) são quase inexistentes no Brasil ${ }^{1}$, pelo menos quanto ao uso dos princípios disciplinadores da ética militar. Talvez isto se deva ao fato de os bombeiros militares (BMs) serem associados a uma imagem pública positiva, quase sempre Ihes cabendo o epíteto de "heróis" ou "anjos da vida". Em pesquisa realizada pelo Ibope, em 2018, que mede o índice de confiança da sociedade nas instituições em nosso país, os bombeiros têm-se mantido em primeiro lugar consecutivamente nos últimos dez anos². Afinal, trabalhar com a busca e o salvamento de pessoas em perigo, além da proteção de patrimônios públicos ou privados, como acontece no combate a incêndios, faz com

${ }^{1}$ Exceção feita ao trabalho de Silva (2015) e Sena (2017).

2IBOPE. Confiança do brasileiro nas instituições é a mais baixa desde 2009 (2018). 
que os "soldados do fogo" sejam reconhecidos pelo risco da profissão, já que arriscam suas vidas por uma causa considerada nobre.

Todavia, pelo fato de o primeiro autor deste texto ter como área de pesquisa as Polícias Militares, não foram poucas as vezes em que se deparou com depoimentos de policiais militares que sempre indagavam: "Já pesquisou os bombeiros? Eles são piores do que nós com o uso do militarismo!" E foram tais observações que despertaram nosso interesse para tentar melhor compreender o militarismo dos bombeiros. Deve-se notar que os CBMs, juntamente com as Polícias Militares (PMs), estão elencados no art. 144 da Constituição Federal de 1988 (Brasil, 1988) como órgãos de Segurança Pública e, também juntamente com as PMs, constituem instituições estaduais cujos profissionais carregam o emblema do militarismo. Por muitos anos, no Brasil, os CBMs foram instituições subordinadas às Polícias Militares. Atualmente, quase todos os Corpos de Bombeiros estão emancipados das PMs nos estados da federação (Costa, 2002), mas permanecem sob a lógica dos princípios militares (hierarquia e disciplina) de acordo com a Constituição de 1988, por serem forças auxiliares e reserva do Exército. Além dos princípios formais herdados constitucionalmente do Exército, PMs e CBMs também permaneceram reproduzindo a lógica cultural das Forças Armadas, o que se exemplifica pelo uso dos trotes na formação pedagógico-profissional e do currículo oculto (Albuquerque; Machado, 2001a, 2001b; França, 2013; Silva, 2002).

O que deve ser indagado é, portanto, como os princípios da cultura militar são vivenciados pelos BMs? Quais as consequências da presença de uma pedagogia do sofrimento na formação do bombeiro militar? Responderemos a tais indagações refletindo sobre o caso da morte do aluno 
soldado Rodrigo Claro, que faleceu em 2016, ironicamente, durante uma instrução de salvamento aquático, na cidade de Cuiabá, no Mato Grosso ${ }^{3}$.

Este trabalho reflete uma pesquisa documental de caráter qualitativo, da qual se destaca aqui o Relatório final do Inquérito Policial Civil ${ }^{4}$ (IPC) disponibilizado para a pesquisa pela Delegacia Especializada de Homicídio e Proteção à Pessoa da cidade de Cuiabá, responsável pelo caso da morte do aluno soldado bombeiro Rodrigo Claro. Deste documento, analisamos 41 folhas, contendo os pontos centrais dos principais depoimentos testemunhais, bem como uma apreciação sobre o laudo necroscópico. Para preservar a identidade das testemunhas, utilizamos nomes fictícios, porém, pela repercussão midiática do caso, o nome da vítima foi utilizado. Quanto à acusada, utilizamos as iniciais do nome, já que o processo do caso não corre em segredo de justiça. Nossa intenção é buscar compreender como ocorrem os processos de socialização/formação dos BMs, e se tais processos podem ser equiparados a uma pedagogia do sofrimento (França; Farias, 2015). Para tanto, iniciaremos por uma síntese histórica acerca da ética militar e do modo como a organização castrense influenciou os CBMs no Brasil. Depois, refletiremos sobre como a violência na formação profissional do BM, através do sofrimento físico, psíquico e moral, se revela como um fenômeno associado à ética militar que impregna a corporação.

\footnotetext{
${ }^{3} \mathrm{O}$ caso teve ampla repercussão na mídia e trata-se da morte do jovem Rodrigo Patrício Lima Claro. Até a feitura deste artigo (março de 2018), a Tenente do Corpo de Bombeiros do Mato Grosso, I. L. S. D., está sendo julgada pelo crime de tortura infligida ao jovem Rodrigo. Mas o que nos importa, independentemente do resultado do julgamento, são as provas testemunhais do fato, as quais são capazes, segundo o IPC, de demonstrar a funcionalidade de uma pedagogia do sofrimento na formação bombeiro militar.

${ }^{4}$ Agradecemos à Delegacia Especializada de Homicídio e Proteção à Pessoa da cidade de Cuiabá, na pessoa da Delegada Titular, pela disponibilização dos dados analisados neste artigo.
} 


\section{Os "soldados do fogo" e o militarismo dos Corpos de Bombeiros}

A atuação dos bombeiros militares nas ruas realizando atendimento pré-hospitalar, nos mares, rios e lagoas salvando pessoas de afogamento, em prédios e casas em chamas, combatendo o fogo em florestas, produz imagens capazes de construir no imaginário coletivo a visão de homens e mulheres virtuosos e corajosos, verdadeiros "heróis". Logo, tais imagens devem levar, também, a refletir sobre as dificuldades enfrentadas pelos bombeiros durante a formação e o treinamento que os habilitam à profissão, a qual, como já dito, em todos os estados brasileiros carrega o emblema do militarismo. Existem também no Brasil bombeiros civis ou brigadistas profissionais, os quais tiveram a profissão regulamentada pela Lei no 11.901, de 12 de janeiro de 2009 (Brasil, 2009) e atuam de forma privada, não sendo agentes estatais como os BMs. É exatamente o adjetivo militar que faz com que os bombeiros militares sejam reconhecidos como os "soldados do fogo". Na letra da Canção do soldado do fogo, uma espécie de hino oficial dos BMs em nosso país, reproduzida a seguir, percebemos como se destacam ideais de guerra misturados com a missão institucional de "vida alheia e riquezas salvar":

Contra as chamas e lutas ingentes

Sob o nobre alvirrubro pendão, Dos soldados do fogo valentes, É a paz, a sagrada missão.

E se um dia houver sangue e batalha.

Desfraldando a auriverde bandeira,

Nossos peitos são férreas muralhas,

Contra audaz agressão estrangeira.

Missão dupla o dever nos aponta:

Vida alheia e riquezas salvar

$\mathrm{E}$, na guerra punindo uma afronta

Com valor pela pátria lutar.

[...]

Rija luta aos heróis aviventa,

Inflamando em seu peito o valor, 
Para frente que importa a tormenta

Dura marcha de sóis ou rigor?

Nem um passo daremos atrás,

Repelindo inimigos canhões

Voluntários da morte na paz,

São na guerra indomáveis leões (Menezes, 2007, grifos nossos).

Os termos em destaque revelam como o ideal bélico está presente de forma ideológica na atividade dos BMs. Se, ao contrário das PMs, os bombeiros não precisam ir às ruas promover policiamento ostensivo fardado para manter a ordem pública ${ }^{5}$, ainda assim, a força discursiva da letra da canção traduz bem como as prerrogativas militares influenciam a profissão, visto que se deve, em "missão", caso haja "sangue e batalha", "com valor pela pátria lutar". Para tanto, "repelindo inimigos canhões", "na guerra punindo uma afronta", os bombeiros também devem ser "indomáveis leões". Não por acaso, Cavalcanti (2002), que é Tenente-Coronel da Reserva da PM pernambucana, ao escrever sobre a história dos bombeiros militares de Pernambuco, escolhe para título do seu livro "Guerreiros da paz", o que mostra como a força da cultura militar sempre antecede os propósitos civis da profissão.

Os primeiros bombeiros surgiram como uma especialidade da Marinha para combater incêndios em navios, os quais eram fabricados de madeira, e receberam a denominação de bombeiros exatamente por operarem bombas d'água (Guimarães, 2017). No Brasil, a história dos Corpos de Bombeiros inicia-se a partir da chegada da família real portuguesa, no início do século XIX, mas somente em 1856 o imperador D. Pedro II cria o Corpo de Bombeiros Provisório da Corte (Toassi, 2008). Inicialmente, os Corpos de Bombeiros não eram militares, isto vindo a ocorrer a partir de 1880, com a justificativa de tornar a instituição mais organizada e eficiente. Em 1881, através do Decreto no 8.337, de 17 de dezembro (Brasil, 1881), os profissionais do Corpo de Bombeiros da Corte passavam a poder ser

${ }^{5}$ Exceção que ocorre durante os processos eleitorais, quando os bombeiros militares são empregados em serviços policiais. 
empregados na guerra como "sapadores"6 ou "pontoneiros"7, estando organizados em um batalhão de engenheiros (Guimarães, 2017). Em 31 de dezembro de 1887, a Princesa Isabel aprovou a reforma do Corpo de Bombeiros da Corte, através do Decreto no 9.829 (Brasil, 1887), mantendo a organização da instituição nos moldes militares (com um quadro hierárquico dividido entre Praças e Oficiais), assim como a convocação para a guerra nas mesmas funções do Decreto de 1881.

Este modelo organizativo ensejou que os Corpos de Bombeiros fossem ratificados legalmente como forças auxiliares do Exército, com possibilidades de convocação para a guerra, a partir do Decreto no 11.497, de 23 de fevereiro de 1915 (Brasil, 1915). Antes, em 1912, no Rio de Janeiro, tinha sido criada a primeira escola do Corpo de Bombeiros, a Escola Regimental, comandada por Oficiais do Exército e que oferecia estudos de nível médio e primário aos que necessitavam de alfabetização, ou ainda a possibilidade de continuar os estudos no Curso de Formação de Oficiais. Além disso, a Escola Regimental passa a formar e instruir também os sargentos bombeiros (Dalabeneta, 2015).

A influência da cultura militar se fez presente nos nascentes Corpos de Bombeiros em todo o país. Nas instituições mais antigas, criadas ainda no século XIX, o motivo principal para a fundação dos CBMs era a falta de uma instituição especializada no combate a incêndios. Quando o Corpo de Bombeiros Provisório da Corte foi criado, em 1856, o Major do Corpo de Engenheiros do Exército, João Batista de Castro Moraes Antas, foi quem assumiu a direção geral. Na então província do Grão-Pará, em 1882, desembarcaram em Belém, para fundar o Corpo de Bombeiros, vindos do Rio de Janeiro, o Capitão Antônio Veríssimo Ivo de Abreu, acompanhado de um Sargento e dois Cabos, juntamente com material de trabalho (Menezes, 2007). Como relata Cavalcanti (2002), a Companhia de Bombeiros de Pernambuco foi criada em 1887, na cidade do Recife, e teve como comandante o Capitão Joaquim José Aguiar, que também

${ }^{6}$ Soldado responsável por desenvolver atividades variadas de engenharia militar.

${ }^{7}$ Soldado da arma de engenharia responsável pela construção de pontes. 
pertencia ao Corpo de Bombeiros da Corte, sediado no Rio de Janeiro, a capital imperial. Juntamente com ele foram deslocados para Recife um Tenente, um Chefe de bomba e um Soldado. Em Santa Catarina, o Corpo de Bombeiros foi organizado em 1926, quando da chegada do $1^{\circ}$ Tenente Domingos Maisonette e dois Sargentos auxiliares, também oriundos do Rio de Janeiro, que era a capital da República. O $1^{\circ}$ Tenente teve como estudantes homens que serviam em áreas diversificadas da então Força Pública (hoje Polícia Militar), em um total de 28 homens (Dalabeneta et al., 2016).

Em 1917, a Lei no 3.216, de 3 de janeiro (Brasil, 1917), torna mais claro em seu texto que, tanto a Brigada Policial do Distrito Federal, como o Corpo de Bombeiros da capital federal e as polícias militarizadas dos estados passavam a constituir forças auxiliares do Exército nacional (artigos 7으 e 8o․). Com exceção do Corpo de Bombeiros do Rio de Janeiro, que era a capital da República, os demais Corpos criados nos estados foram subordinados às Forças Públicas, mais tarde Polícias Militares, o que pode ser encontrado no texto do Decreto-Lei no 8.660, de 14 de janeiro de 1946 (Brasil, 1946), que especifica em seu Art. 3ำ que os Corpos de Bombeiros dos estados só poderiam possuir organização militar caso fossem incorporados às respectivas forças policiais. No caso das PMs, desde a Constituição de 1934, elas já eram consideradas reservas do Exército (Krok, 2008).

Na Constituição de 1967 (Brasil, 1967a), em pleno regime militar, de acordo com o Art. 13, parágrafo 4, em modificação à Constituição de 1946, os Corpos de Bombeiros, assim como as PMs, passavam a ser forças auxiliares e reserva do Exército para a manutenção da ordem e segurança interna nos estados, territórios e Distrito Federal. Durante todo o período ditatorial (1964-1985), as PMs e os CBMs estiveram subordinados ao Exército brasileiro como forças auxiliares e, nesta época, em todos os estados, PMs e Corpos de Bombeiros possuíam os mesmos integrantes, de modo que, "na prática, ora o militar estadual atuava como policial no combate à subversão e na manutenção da ordem pública, ora atuava no combate a incêndio e na função de defesa civil, desenvolvendo uma 
interação de caráter cívico-social" (Krok, 2008, p. 41-42). No Pará, por exemplo, onde os CBMs permaneceram subordinados às PMs de 1971 a 1990, segundo as palavras de um Coronel: "os Bombeiros eram tratados como filhos bastardos. Sem nenhuma formação policial, eram obrigados a tirar serviço de Polícia. Desde Oficial ou Superior de Dia até comandar ações tipicamente policiais. [...] fugindo completamente à nossa formação profissional..." (Menezes, 2007, p. 181).

Foucault também observa o fenômeno de aproximação entre polícias e bombeiros ao afirmar que "ao bombeiro podemos pedir para ser um complemento de polícia. O conjurador do fogo tornou-se uma força da ordem. 'Tiras, bombeiros-tiras, todos colegas, todos defensores da ordem, todos homens-porretes'" (2012, p. 27). Na verdade, no regime militar brasileiro, as ações cívicas eram usadas estrategicamente pelos militares para garantir uma boa imagem junto à população.

Em Santa Catarina, por exemplo, desde a criação de um Centro de Formação para os PMs, em 1927, o mesmo local era usado para formar os oficiais bombeiros militares com conhecimentos policiais. Os conhecimentos específicos da função de bombeiro eram adquiridos por meio de especializações, quando o oficial BM adquiria a transferência da PM para o CBM ou havia indicação de um superior hierárquico. Quanto aos praças, a formação era realizada juntamente com os policiais militares nas companhias e batalhões espalhados pelo estado, até o ano de 1993, quando foi criado um centro de formação para praças PMs em Santa Catarina. De todo modo, o local também passou a formar praças BMs, só que o conhecimento ensinado já era diferenciado para ambas as corporações (Dalabeneta, 2015).

Com a aprovação do Decreto-Lei no 317, de 13 de março de 1967 (Brasil, 1967b), que reorganizou as PMs e os CBMs, criou-se também a Inspetoria Geral das Polícias Militares (IGPM), órgão do Exército que ampliou a subordinação, o controle e fiscalização sobre aquelas instituições. O dado a se observar é que, dos trinta artigos do Decreto-Lei, apenas um (Art. 28) refere-se aos CBMs, ressaltando que todas as disposições atinentes às PMs 
aplicam-se também aos bombeiros, salvo exceção dos Artigos 5o e 6으 e seus parágrafos ${ }^{8}$. A posteriori, o Decreto-Lei no 667, de 2 de julho de 1969 (Brasil, 1969), novamente reorganizou as PMs e os CBMs com alteração de alguns artigos do Decreto-Lei no 317. Em 24 de junho de 1975, aprovase o Decreto-Lei no 1.406 (Brasil, 1975), que alterava especificamente o parágrafo único do Art. 26 do Decreto de 1969, acrescentando aos CBMs o alcance dos Artigos 6ํㅜ e 7ํㅡㄹ e seus parágrafos ${ }^{9}$, que eram relativos apenas às PMs. Em 12 de janeiro de 1983, houve outra alteração na organização das PMs e dos CBMs com a aprovação do Decreto-Lei no 2.010 (Brasil, 1983a), ao qual seguiu o Decreto-Lei no 88.777, de 30 de setembro de 1983 (Brasil, 1983b), que aprovava o regulamento do Exército (R-200) às PMs e aos CBMs. Neste último, tornava-se claro que os BMs, à semelhança dos PMs, para serem considerados militares e forças auxiliares reserva do Exército, passavam a ser controlados e coordenados pelo Ministério do Exército; poderiam ser componentes das PMs, ou não, desde que, neste último caso, tivessem condição de vida autônoma, proporcionadas pelas Unidades da Federação e pelo Estado-Maior do Exército; e, deveriam ser estruturados com base na hierarquia e disciplina.

Percebe-se que a aprovação de tantos Decretos-Lei, em curto espaço de tempo, era uma forma de o governo militar manipular a utilização das PMs e dos CBMs, de modo que "os policiais militares ficaram sujeitos ao trinômio: instrução militar, regulamento militar e justiça militar" (Zaverucha, 2007, p. 33). Pela subordinação direta dos CBMs ao Exército e às PMs, o trinômio também era aplicado aos bombeiros. Essa estratégia fazia com que

${ }^{8} \mathrm{O}$ Art. 5o do Decreto-Lei 317 destaca: "O Comando das Polícias Militares será exercido por oficial superior combatente, do serviço ativo do Exército, preferentemente do posto de Tenente-Coronel ou Coronel, proposto ao Ministro da Guerra pelos Governadores de Estado e de Territórios ou pelo Prefeito do Distrito Federal". Já no Art. 6o encontramos: "Oficiais do serviço ativo do Exército poderão servir no Estado-Maior ou como instrutores das Polícias Militares, obedecidas para a designação as mesmas prescrições do artigo anterior, salvo quanto ao posto".

${ }^{9} \mathrm{O}$ Art. $6^{\mathrm{o}}$ do Decreto-Lei 667 tem como redação os mesmos termos do Art. 5o do DecretoLei 317 e o artigo 70 também copia, quase que na íntegra, o Art. 6o do Decreto-Lei 317, com o acréscimo de que, para que um oficial do Exército servisse no Estado-Maior ou como instrutor das PMs, era preciso que o Comandante da PM fosse também oficial do Exército. 
o contingente das Forças Armadas e forças estaduais (PMs e BMs) chegasse a um total de quase 500.000 homens, os quais poderiam ser mobilizados pelo Governo Federal em exercício na ditadura (Krok, 2008).

Torna-se fato que a centralização regulamentar dos Corpos de Bombeiros, durante tantos anos, pela esfera administrativa militar não poderia deixar de influenciar a cultura organizacional, legitimando a existência dos "soldados do fogo". E, ao contrário do que se esperava, a Constituição de 1988 manteve os CBMs como instituições militares. No Art. 42, especifica-se que os bombeiros são servidores militares estaduais junto com os PMs e, no Art. 144, inciso V, os CBMs figuram, juntamente com as PMs, como órgãos de Segurança Pública. O parágrafo 5o ainda regula que, além das atribuições definidas em lei, aos CBMs compete a execução da defesa civil e, o parágrafo 6ํㅜ ratifica o legado autoritário e classifica os CBMs como força auxiliar e reserva do Exército ao lado das PMs, sendo diretamente subordinados, junto com as Polícias Civis, aos governadores estaduais (BRASIL, 1988).

Podemos afirmar que a produção acadêmica acerca da formação dos bombeiros militares ainda é incipiente, ao contrário das PMs, para as quais já existe bibliografia ${ }^{10}$ que correlaciona o ethos guerreiro da profissão e a possível violência praticada nas ruas como reflexo de uma "pedagogia do sofrimento" (França; Farias, 2015). Ainda assim, a produção acadêmica existente revela-nos que, embora os bombeiros não produzam violência externa, como a praticada pelos PMs quando desenvolvem o policiamento ostensivo nas ruas, resta-lhes a violência institucional para preencher os princípios da ordem e obediência.

Em pesquisa sobre os bombeiros militares de Santa Catarina, durante as entrevistas, Toassi (2008) revela como os entrevistados se precaviam das críticas ao militarismo, fazendo referências veladas para evitar possíveis punições devido às opiniões externadas. Em outra pesquisa, também sobre BMs de Santa Catarina, uma supervisora pedagógica entrevistada afirma que: "alguns instrutores Bombeiros enxergam o aluno soldado como... nada, ${ }^{10}$ Ver Albuquerque e Machado (2001a, 2001b), França e Farias (2015) e Silva (2002). 
ou pouco menos que nada. Tem gente que chega e fala: 'Ah, o aluno é tudo bicho do demônio'" (Dalabeneta, 2015, p. 102-3). Um instrutor, na mesma pesquisa, ao dividir a aula ministrada aos soldados BM com outro instrutor que foi formado no Exército relata que este último dizia: "Tá errado, é assim, seu bisonho ${ }^{11}$, seu isso, seu aquilo", o que gerava medo nos alunos na hora de dirimir dúvidas sobre a aula (Dalabeneta, 2015, p. 138, grifo do autor).

Em análise sobre a aplicação da Matriz Curricular Nacional ao Curso de Formação de Soldados BM do Pará, constata-se como a força da cultura e da administração militar impede mudanças que possam promover certa autonomia aos soldados BM, considerados apenas como elementos de execução. Nas palavras de um Tenente instrutor BM: "Nosso medo enquanto instrutores é que eles (soldados) pensem demais, comecem a questionar algumas coisas que vão de encontro ao militarismo" (Silva, 2015, p. 64). Um Soldado BM entrevistado acrescenta: "Os instrutores de formação militar não permitem a gente fazer um questionamento, não era aceito, acabava impedindo a troca de conhecimento" (Silva, 2015, p. 69).

A formação dos Soldados Bombeiros Militares não se destina somente a ensinar os procedimentos tanto operacionais quanto administrativos atinentes ao desenvolvimento profissional, também se ocupa em construir um padrão de comportamento que se encontra relacionado com seu papel institucional de executor, que se reflete na predominância de disciplinas militares e técnicas, em detrimento de disciplinas que ensejem o debate e a valorização de experiências anteriores que possam gerar desta forma, questionamentos que possam vir a contrariar a estrutura estabelecida histórica e culturalmente (Silva, 2015, p. 44-5).

As situações antes expostas, de certa forma, traduzem a força do sistema militar sobre os indivíduos que o experienciam, já que a disciplina, a hierarquia e a obediência são os seus pilares fundamentais, os quais existem regulamentados em códigos prescritos exercendo vigilância contínua sobre

${ }^{11}$ Segundo Dalabeneta (2015), bisonho é uma expressão nativa da cultura militar de caráter pejorativo e depreciativo, quando usada contra um subordinado. 
todos os gestos, olhares e palavras dos militares (Foucault, 1987). Desse modo, como o sistema militar objetiva disciplinar corpos que produzam violência tanto física quanto simbólica, a ordem surge caracterizando-se como um aguilhão que fere aquele(a) que a recebe. E a ordem enquanto aguilhão, com toda a violência a ela atrelada, tenta encontrar maneiras de se exteriorizar, o que faz do militarismo seu modelo par excellence.

A acumulação progressiva desses aguilhões no soldado é um processo que avança rapidamente. Em se tratando de um soldado raso, o grau mais baixo da hierarquia militar, toda e qualquer oportunidade de livrar-se de seus aguilhões permanece-lhe vedada, pois não lhe é possível dar ordem alguma. Faz sempre o que the mandam. Obedece e, em sua obediência, torna-se cada vez mais rígido (Canetti, 1995, p. 316).

Nesse contexto, os aguilhões da ordem chegam ao extremo quando o sofrimento infligido aos alunos militares faz parte dos ritos institucionais, legitimando o currículo oculto, em muitos casos acrescidos de violência física. O currículo oculto, nas escolas militares, é utilizado no cotidiano paralelamente ao currículo formal, incutindo nos alunos ideais como a honra, o brio, a força, o vigor, de modo que essa perspectiva curricular se traduz na valorização dos símbolos militares (Cerqueira, 2009). Não por acaso, os testes e instruções militares estão culturalmente sedimentados por elementos da "dominação masculina" (Bourdieu, 2002), pois, se em relação à mulher foi socialmente construída a visão pejorativa de sexo frágil, ao homem dominador torna-se "natural" o sofrimento para se obter um "brevê de virilidade militar"12 (Bertaud, 2013a). Às mulheres, para serem aceitas em um mundo de predominância masculina, cabe também internalizarem a "sobredeterminação militar" (Calazans, 2004), aprendendo pela lógica

\footnotetext{
${ }^{12}$ Brevês, na cultura militar, são símbolos usados no uniforme indicativos do término de cursos pelos militares. Cada brevê carrega consigo distinções sociais e institucionais que referencia a pessoa que o possui diante do grupo de militares, especialmente quando são símbolos que identificam o término de um curso desgastante nos quais as dores físicas e morais chegam ao extremo, exigindo, muitas vezes, momentos de superação que vão além da resistência corporal e psicológica. Ver Bertaud (2013a).
} 
dos ensinamentos militares como a violência é inerente à incorporação do ethos militar.

Em relação aos bombeiros militares, a utilização do currículo oculto faz parte da cultura interna por meio principalmente dos trotes ${ }^{13}$ e das instruções. Um dos mais conhecidos na cultura dos bombeiros é o "caldo", o qual é aplicado nas aulas em piscinas, em rios ou no mar. No "caldo", o(a) aluno(a) é forçado(a) por alguém que faz pressão por cima de sua cabeça empurrando-o(a) com violência até a submersão. Ao perder o fôlego, o(a) aluno(a) tenta colocar a cabeça para fora d'água, mas é impedido(a), de modo que o "caldo" repete-se por inúmeras vezes. Foi exatamente na aplicação de um "caldo", durante uma instrução de salvamento aquático, que ocorreu o caso que adiante analisamos.

\section{Socialização e sofrimento na formação do bombeiro militar}

A pedagogia do sofrimento diz respeito à aplicação do sofrimento físico, moral e psicológico a alunos militares, não importa se das Forças Armadas, Polícias Militares, Bombeiros Militares ou escolas militares congêneres que adotem a organização e a ética simbólica do militarismo. É um tipo de perspectiva pedagógica, baseada no disciplinamento corporal e psíquico (Foucault, 1987), a partir da qual se destaca o currículo oculto e informal, com destaque para a violência pautada na rusticidade, virilidade, machismo, espírito de corpo (camaradagem entre os militares), brio, superação, honra em fazer parte de um grupo com características distintivas. Ao utilizarmos as palavras de Bertaud sobre a origem do Exército moderno francês, poderíamos dizer que a pedagogia do sofrimento se alinha à ética militar de modo que,

\footnotetext{
${ }^{13} \mathrm{O}$ trote trata-se de um "rito de passagem" (Van Gennep, 2011) ou "rito de elevação de status" (Turner, 2013) no qual impera o sofrimento físico, psíquico e moral aplicado de forma individual ou coletiva por veteranos a novatos que ingressam principalmente na carreira militar ou no ensino universitário. Acontece por meio de testes físicos de superação e/ou através de situações constrangedoras, humilhantes e vexatórias. Ver também (Mattoso, 1985) e (Zuin, 2002).
} 
A força e a resistência ao cansaço, a aptidão para superar o sofrimento físico e a dor moral, enfim, a aceitação de derramar seu sangue para a defesa do país são um conjunto de qualidades viris que encontram sua completa satisfação no estado militar. Os exercícios físicos e as manobras militares criam um indivíduo de corpo alinhado e aspecto tão característico que se reconhece neles o militar mesmo quando estão sem uniforme. Muitos sofrimentos marcam a carne e o espírito do recruta até que ele chegue a possuir a forma de soldado. A instrução militar se dá, com efeito, muitas vezes, sob o temor permanente da punição e em meio a gritos, insultos e golpes (Bertaud, 2013a, p. 74-85).

Entre "gritos, insultos e golpes", no caso dos bombeiros militares no Brasil, houve uma adaptabilidade do currículo oculto das Forças Armadas para os "soldados do fogo". Em 2008, por exemplo, um Sargento de 34 anos e 15 anos de profissão faleceu durante uma instrução em um curso de mergulho no Lago Paranoá, em Brasília. A versão relatada pelo Comando dos Bombeiros, à época, foi que o Sargento teria desmaiado após nadar certo percurso. Testemunhos contraditam a versão oficial e relatam que o sargento teria sido deixado por um barco 500 metros distante da margem e, "no percurso, mergulhadores dos bombeiros, apelidados de 'tubarões', davam o que eles chamam de 'caldo', ou seja, dificultavam o nado, segurando e afundando o militar. Em um desses 'caldos', Nunes teria se afogado e não pôde ser reanimado"14. Em 2013, quatro bombeiros militares foram condenados a cumprir um ano de prisão pela morte do sargento ${ }^{\mathbf{1 5}}$.

Essa crença coletiva baseada em uma formação pautada no sofrimento como herança das Forças Armadas (França; Farias, 2015; Albuquerque; Machado, 2001a) serve para alimentar um imaginário de que, na guerra, a covardia deve ser superada, assim como o cansaço. Ao reproduzir estas práticas culturais de ordem organizacional, os bombeiros militares exercem sofrimento sobre seus próprios componentes. Outro exemplo ocorreu em 2014, em Rondônia, com a morte do bombeiro militar Aussiner Dutra Ferreira. Por ironia do destino, ele morreu afogado em uma piscina durante

${ }^{14}$ Portal G1. Bombeiro morre durante treinamento em Brasília (2008).

${ }^{15}$ Portal R7. Justiça condena bombeiros militares por provocar morte de sargento em treinamento de mergulho (2013). 
treinamento de afogamento. A vítima, juntamente com outros colegas, estava na piscina há mais de três horas realizando exercícios. Quando foram liberados por um auxiliar, receberam uma ordem contrária do Tenente Coordenador do curso, de modo que todos retornaram à piscina para realizar novos exercícios. Devido ao cansaço extremo, a vítima e outro colega começaram a passar mal. Temendo o pior, colegas tentaram ajudar os dois, o que também foi proibido pelo Tenente, para que eles se virassem sozinhos. O colega conseguiu alcançar a borda da piscina, ao contrário de Aussiner, que afundou e se afogou. Mesmo sendo resgatado, não sobreviveu. O Tenente foi condenado a dez anos de reclusão por tortura seguida de morte ${ }^{16}$. Novamente, o que está em jogo é a crença de que o militar deve ser capaz de autossuperação, por isso a ordem do Tenente para que Aussiner, mesmo estando exausto, conseguisse sair da situação adversa. Essa prática também é comum em cursos policiais militares para tropas especiais.

Era o terceiro dia do curso e, dos 34 policiais que o iniciaram, 8 já haviam "pedido para sair", desistindo de continuar no programa de treinamento. O "turno" de alunos estava mergulhado na água fria do mar por duas horas; tal condição intensificava o sofrimento, pois eles não dormiam desde a "Aula Inaugural", ocorrida no início do treinamento. Toda vez que um aluno não conseguia se manter unido aos demais e se desgarrava do grupo, era empurrado pelas ondas do mar até a praia, provocando a reação do instrutor: "O Turno deixou mais um integrante se desgarrar. Aluno! Volte para sua equipe e informe ao xerife que será acrescido mais $15 \mathrm{~min}$ na água, além do tempo previsto para o exercício!" (Storani, 2008, p. 11).

No caso aqui em análise, o fato ocorreu no dia 16 de novembro de 2016. Conforme informações do IPC, Rodrigo Claro, de 21 anos, estava na condição de aluno soldado do 16ํㅡㄹ Curso de Formação de Soldado Bombeiro Militar do Estado do Mato Grosso. Na data de 10 de novembro de 2016, após ter participado de uma aula de salvamento aquático na

${ }^{16}$ Portal G1. Tenente bombeiro é condenado a dez anos de prisão e perde cargo, em RO. (2014). 
Lagoa Trevisan, em Cuiabá, deu entrada no Hospital Jardim Cuiabá, às 20h40, com quadro de hemorragia cerebral e crises convulsivas, vindo a óbito às 21 h00 do dia 15 de novembro de 2016. A mãe da vítima registrou ocorrência (BO n. 2016.366460), o que levantou inicialmente indícios de crime de tortura e homicídio doloso na forma tentada, tendo como principais acusados o Coronel coordenador do curso e a Tenente I. L., instrutora de salvamento aquático.

As informações prestadas em depoimento pela mãe da vítima são os relatos que the foram repassados por três alunos que participavam da aula com Rodrigo, de modo que

a vítima, durante a travessia da Lagoa Trevisan, em 10 de novembro de 2016, recebeu diversos "caldos" da Instrutora Tenente BM L., ocasionando total desespero em seu filho, bem como episódios de vômitos e dores de cabeça. Que a vítima chegou a implorar para que a Instrutora cessasse os afogamentos e igualmente pediu para não realizar o retorno da travessia, mas que foi obrigado a continuar, sendo praticamente carregado pelos colegas. Maria ${ }^{17}$ prossegue dizendo que a vítima deixou o local da atividade por meios próprios, sob ordem da Tenente BM L. e se apresentou ao Tenente Coronel Freitas (IPC, p. 3-4).

Como se vê, a palavra "caldo" aparece no depoimento relacionada à consequência de ocasionar "total desespero na vítima", o que teria gerado o fato de a vítima "implorar para que a Instrutora cessasse os afogamentos".

Segundo o depoimento dos três alunos, que foram os que mais próximos estavam de Rodrigo durante a instrução, ao falarem sobre o comportamento da Tenente durante as aulas, "desde o começo do curso, sempre quando a via ensinar ou falar com o pelotão, a via sempre proferindo palavras de baixo calão, ridicularizando, proferindo xingamentos" (Depoimento do aluno Caldas, IPC, p. 5); "Sentia-se humilhado especialmente pela Tenente L. que nessas oportunidades thes chamavam de lixo e ainda utilizava de palavras de baixo calão" (Depoimento do aluno Fonseca, IPC, p. 6); "Que ao contrário do que esperava de seu Comandante, a Tenente BM

${ }^{17}$ Nome fictício, assim como todos que aparecerem em se tratando das testemunhas. 
L. os humilhava, chamando o pelotão de lixo, de burro e que por muitas oportunidades sentiu-se humilhado e depreciado como ser humano" (Depoimento do aluno Lima, IPC, p. 6). Em resumo, "a Tenente BM L. se impunha pelo autoritarismo e não pelo respeito" (IPC, p. 6). Ainda segundo palavras do aluno Caldas, a Tenente tinha conhecimento dos alunos que sentiam dificuldades para nadar, entre eles a vítima, e geralmente os tratava por "muquiço, monstros, burros". As palavras dos depoentes são regulares quanto às ofensas morais apresentadas pela Tenente na forma de tratamento dispensada aos alunos, do mesmo modo como observado em outros estudos sobre formação militar (Castro, 2004; Albuquerque; Machado, 2001a, 2001b; Bertaud, 2013a; França; Farias, 2015).

O aluno Fonseca nos relata bem a funcionalidade do "caldo" ao depor que, nas primeiras aulas na piscina da UFMT ${ }^{18}$, a vítima e outro aluno chegavam a vomitar pela grande ingestão de água devido aos "caldos" que a Tenente BM L. impunha aos mesmos. Esses caldos eram praticados pela Tenente da seguinte forma: "ela se apoiava com as duas mãos nos ombros dos colegas, fazendo-os submergir na água... Além de os submergir, os segurava por alguns segundos embaixo d'água" (Depoimento do aluno Fonseca, IPC, p. 7). Caldas acrescentou que a vítima, certa vez, apresentou um atestado médico de 10 dias que a impedia de participar de aulas práticas, de modo que "tal situação causou bastante irritabilidade na Tenente BM L., que publicamente disse que a vítima estava com 'froxura' e o comparou à uma $\mathrm{FEM}^{19}$, ou seja, a uma soldado mulher" (IPC, p. 7). Quanto às palavras do aluno Fonseca, podemos entender bem o que vem a ser o "caldo" por sua percepção, já quanto ao exposto pelo aluno Caldas, a comparação da vítima a uma mulher mostra a internalização pela Tenente da lógica da "sobredeterminação militar" estudada por Calazans (2004), a qual diz respeito à naturalização da violência por mulheres que ingressam na carreira militar.

\footnotetext{
${ }^{18}$ Universidade Federal de Mato Grosso.

${ }^{19}$ FEM é uma expressão pejorativa da cultura militar para se referir às mulheres como inferiores. Ver Souza (2012).
} 
Ainda sobre a prática do "caldo", as testemunhas descrevem em seus depoimentos como teria ocorrido durante a aula de salvamento aquático na Lagoa Trevisan, logo após o início da travessia da lagoa e quando a vítima começou a apresentar sinais de cansaço:

[A] Tenente BM L. o agarrou por trás [a vítima], no que ele começou a submergir... Via que ele fazia muito esforço para subir, no que ela largava e jogava água no rosto dele e, em seguida, voltava a subir em cima dele, desta vez o empurrando para baixo... Vendo que ele não estava tendo forças para subir, o Aluno Lima mergulhou e empurrou os dois para cima... Voltava a repetir a sessão que ela e demais oficiais chamam de CALDO, mas que na visão do depoente, seria afogamento (Depoimento do aluno Caldas, IPC, p. 8).

Ainda mais, nas palavras das outras testemunhas:

Percebeu a aproximação da Tenente BM L. e visualizou a oficial segurando na cintura de RODRIGO, dificultando com que o mesmo conseguisse bater as pernas. Que pode observar que a Tenente BM L. chegou a efetivar uns dois "caldos" em Rodrigo, submergindo-o na água da lagoa. Que o depoente pode presenciar a Tenente BM L. segurando Rodrigo pela cintura, puxando o mesmo para baixo, quanto subindo em seus ombros, afundando-o na Lagoa...o segurava por alguns segundos. Que ficou claro para o depoente que Rodrigo nesses "caldos", ingeriu bastante água" (Depoimento do aluno Fonseca, IPC, p. 8).

"Percebeu que aproximadamente depois de 05 a 08 metros de travessia, Rodrigo já não conseguia mais nadar...o depoente passou a auxiliá-lo. Que o depoente percebeu a aproximação da Tenente BM L., que falava com Rodrigo, mas o depoente não conseguia discernir. Que com a aproximação da Tenente BM L., o depoente já desconfiava que Rodrigo tomaria um "caldo", então tentava sincronizar o movimento de segurá-lo pela axila com o movimento da Tenente BM L. de se apoiar nos ombros de Rodrigo para submergi-lo. Que neste movimento de tentar levantar Rodrigo, o próprio depoente submergia e quando emergia, a Tenente BM L. novamente aplicava o "caldo", afundando Rodrigo. Que o depoente então submergia para emergir Rodrigo. Que não pode precisar quantos "caldos" a Tenente BM L. aplicou em Rodrigo, mas que foram mais que dois...que ainda pode observar que a Tenente BM L. segurou Rodrigo pela cintura e dizia que pararia de auxiliá-lo batendo as 
pernas. Que em seguida a tenente BM L. afundou Rodrigo se apoiando nos ombros do colega. Que a Tenente BM L. quando afundava Rodrigo pela cintura, submergindo-o, o segurava de três a cinco segundos" (Depoimento do aluno Lima, IPC, p. 8-9).

As palavras descritas acima são claras quanto à finalidade do "caldo" que é exercer sofrimento físico na pessoa que o recebe. Como nos esclarece Bertaud (2013a, p. 82-85), "muitos sofrimentos marcam a carne e o espírito do recruta até que ele chegue a possuir a forma de soldado. Nessa atmosfera, os antigos praticam sobre os recrutas a pedagogia da violência". Essa pedagogia da violência, que na verdade reconhecemos ser uma "pedagogia do sofrimento (França; Farias, 2015), na concepção dos militares visa a uma série de objetivos como desenvolver o senso de superar a si mesmo, pois, "[c]om a finalização da primeira etapa, Rodrigo teria gritado que não desejava mais prosseguir no exercício, o que foi ignorado tanto pela Tenente BM L., como pelo Tenente Coronel Freitas que disseram à vítima que ele teria que completar a travessia de retorno" (IPC, p. 9).

Segundo a narrativa dos depoimentos dos alunos no IPC, Rodrigo teria completado a travessia da lagoa sendo "rebocado" pelos colegas e que, ao chegar na parte rasa, teria vomitado e reclamado de dores de cabeça, mas o Tenente-Coronel Freitas teria dito que as dores de cabeça não se relacionavam com a instrução. Por fim, após falar com a Tenente L., Rodrigo teria sido liberado para apresentar-se à Coordenação do Curso e foi embora sozinho. Ao longo do IPC, outros alunos confirmam terem visto o "caldo" aplicado a Rodrigo durante a travessia na lagoa e se reportam também às aulas na UFMT. No entanto, o depoimento do aluno Bandeira afirma:

[...] que nunca notou comportamento de agressão da Tenente BM L., sendo pessoa de conduta firme, dizendo que ensinaria a diferença da vida "paisana" da vida militar. Que nunca presenciou a Oficial perseguindo a vítima, sendo que apenas voltou a atenção para Rodrigo após perceber que o aluno tinha dificuldades. Sobre as aulas nas piscinas da UFMT, o próprio depoente confirma que já foi submetido a "caldos" pela Tenente BM L., descrevendo a conduta da oficial ao praticar tais manobras (IPC, p. 14). 
Ensinar a diferença entre a "vida paisana" e a "vida militar", como observado na fala do depoente, é uma característica que comprova nosso argumento acerca da relação entre a pedagogia do sofrimento e a cultura militar, visto que, ser paisano ou civil é ser considerado socialmente inferior pelos militares (Castro, 2004; Bertaud, 2013a). Nesse sentido, "a virilidade do civil é dom da vida, a do militar é busca de morte" (Bertaud, 2013b, p. 195). Além disso, o não estranhamento do aluno Bandeira em relação à "conduta firme" da Tenente e à prática do "caldo" mostra-o como um exemplo de como a pedagogia do sofrimento funciona de modo reverso em seus resultados. Neste caso, o indivíduo que a sofre naturaliza a violência e a internaliza de modo positivo, como observado nas condutas dos alunos do Curso de Operações Especiais do BOPE da PM do Rio de Janeiro (Storani, 2008).

Entre os instrutores ouvidos no IPC também se comprova a aplicação do "caldo" no aluno Rodrigo. Exceção feita aos praças (dois Sargentos e um Cabo estavam na lagoa), os quais negam ter presenciado o momento do "caldo", o que nos aventa a hipótese de que talvez tenham ocultado informações por serem inferiores hierárquicos da Tenente. No entanto, um Tenente relatou em seu depoimento:

O depoente confirma ter observado a Tenente BM L. realizando "caldos" em Rodrigo, descrevendo o "caldo" como uma força exercida com as mãos, pela Tenente BM L., direcionada na cabeça do aluno Rodrigo, no sentido de submergi-lo e após a submersão, soltar o aluno. Rodrigo, após sofrer os "caldos", novamente se desesperou e apresentava dificuldades para respirar, pedindo que a Tenente BM L. parasse com a conduta de lhe impor os "caldos" (palavras do Tenente Souto, IPC, p. 19).

No depoimento da Tenente L., ela explica quais são os objetivos da disciplina de salvamento aquático e deixa claro que a matéria é ministrada ao final do curso, "oportunidade em que o aluno já teve cerca de 120 horas de treinamento físico militar, inclusive com aulas de natação" (p. 32). Ao invés da natação ser prioridade no curso, aparece como uma atividade secundária, deixando o condicionamento físico dos alunos baseado no "treinamento 
militar", para, apenas ao final do curso, ser realizada a disciplina específica de salvamento aquático. Em outro momento, a Tenente, ao ser "[i]ndagada sobre os relatos de ter aplicado golpes com as nadadeiras nos alunos, explica não serem agressões, tampouco ameaças, mas condutas inerentes ao meio militar" (IPC, p. 34). Novamente, destaca-se no depoimento a naturalização da presença de princípios da cultura militar, neste caso do currículo oculto (Cerqueira, 2009), baseados na violência entendida como algo positivo para a formação.

Na continuidade de seu depoimento, a Tenente nega ter aplicado "caldo" ao aluno Rodrigo e que, na verdade,

neste momento, além de chamar a atenção do aluno, a interroganda aplicou a técnica do "nado resistido" em Rodrigo. Explica que o segurou pela camiseta, na região próxima à cintura, fazendo com que o aluno suportasse a resistência de puxar a interroganda, sendo salientado que em momento algum fez força contrária, continuando a bater as pernas. Na realidade, a técnica é mais psicológica do que física, fazendo com que o aluno raciocine que se ele não desistir de nadar, não terá a presença da Instrutora oferecendo certa resistência (IPC, p. 35, grifo nosso).

Em contraposição ao revelado anteriormente pela Tenente, um TenenteCoronel dos BMs, ouvido como especialista em salvamento aquático, relatou que: "[o]s instrutores e monitores devem evitar colocar o aluno em condição psicológica de total insegurança, visando não dificultar o aprendizado" (p. 38, grifo nosso). Além disso, "foi indagado ao Tenente Coronel se o mesmo conhece a técnica do "nado resistido", o mesmo declarou que não conhece essa técnica" (IPC, p. 38).

Havia a presença de um fotógrafo no local, o qual oferece em seu depoimento a seguinte observação acerca da postura da Tenente: "demonstrou ter um comportamento agressivo na forma de falar e no tratamento com os alunos. Que ela demonstrava ser muito rígida no sentido de cobrar dos alunos a execução das atividades que ela determinava" (IPC, p. 39). 
Segundo o laudo necroscópico, juntado como peça no IPC, a causa da morte de Rodrigo Claro se deu por "hemorragia cerebral de causa natural", não havendo provas quanto à relação causal das atitudes da Tenente L. contra Rodrigo e seu óbito. No entanto, restou ao IPC apurar a responsabilidade pelos atos praticados pela Tenente L. durante a instrução de salvamento aquático, pois, "[e]mbora em seu interrogatório a oficial argumente que se valeu de técnica denominada de "nado resistido", diante dos depoimentos dos alunos, dos monitores e das declarações do especialista ouvido, acreditamos que não prospera a fundamentação da investigada" (IPC, p. 40). Em síntese, o IPC aponta o seguinte resultado:

Consoante os relatos dos alunos, o que ocorreu durante a travessia da Lagoa Trevisan em 10 de novembro de 2016 se amolda a atos de tortura, pois a conduta da oficial se amolda ao disposto no artigo $1^{\circ}$, inciso $/ /$ da Lei n. ${ }^{\circ}$ 9455/97, na medida em que impôs a Rodrigo Patrício Lima Claro, pessoa que estava sob sua autoridade, intenso sofrimento físico e mental, mediante violência e grave ameaça, caracterizados pelos sucessivos "caldos" e posturas coercitivas, como forma de lhe castigar pelo péssimo desempenho e pelo fato de ter apresentado atestados médicos em sua disciplina (IPC, p. 41, grifo nosso).

O que devemos deixar claro é que nossa intenção neste artigo não diz respeito a analisar a conduta antijurídica demonstrada provisoriamente pelos fatos, visto que o processo judicial contra a Tenente L. tramita na justiça. O que podemos dizer, por uma análise sociológica, é que estes casos, especialmente de morte de militares em treinamento (não importa se das Forças Armadas, PMs ou BMs), acabam convertendo-se, segundo nossa ótica, em um fenômeno de "vitimização sacrificial" (Girard, 1990). Cada morte simboliza, ao final, a valorização institucional, a ideia de que não é fácil ser um bombeiro militar, dadas as dificuldades e provações que é necessário superar. As vítimas, na verdade, reforçam os ideais institucionais e suas mortes simbolizam a revalorização do caráter social da instituição.

Com a naturalização da morte por parte dos bombeiros, já que eles se depararão com a morte no cotidiano da profissão, resta a dose de ideologia institucional para fazer do juramento, no ato da formatura (o qual é idêntico 
ao das Forças Armadas e PMs), o momento solene para um compromisso moral que honra a morte. Podemos observar, por exemplo, no Art. 34, da Lei 7.479 de 2 de junho de 1986, que trata do juramento dos BMs do Distrito Federal quando aduz:

Ao ingressar no Corpo de Bombeiros do Distrito Federal, prometo regular minha conduta pelos preceitos da moral, cumprir rigorosamente as ordens das autoridades a que estiver subordinado e dedicar-me inteiramente aos serviços profissionais e à segurança da comunidade, mesmo com o sacrifício da própria vida (BRASIL, 1986, grifo nosso).

Portanto, a pedagogia do sofrimento ainda é uma realidade presente nos Corpos de Bombeiros Militares em nosso país. No caso dos BMs, vários fatores surgem para que este tipo de violência não seja problematizado com mais atenção, tanto por parte de acadêmicos, como pelas políticas públicas, ou seja: os CBMs são instituições respeitadas por salvar vidas, logo, não passam pelos mesmos problemas que as PMs quando lidam com a sociedade; a cultura militar presente nas casernas de BMs geralmente não é associada a valores como o machismo, o autoritarismo institucional e a violência, apesar de os BMs serem formados e grande parte deles trabalharem em quartéis como qualquer outro sob a égide do militarismo, sendo cobrados diuturnamente pelos princípios da disciplina e hierarquia. Além disso, BMs são identificados com figuras simbólicas construídas positivamente, como a de herói, o que ajuda a desviar o interesse da sociedade como um todo para a violência intra corporis sofrida pelos soldados do fogo, de maneira que só eles devem saber o que passam para vencer as batalhas vivenciadas institucionalmente. 


\section{Conclusões}

Em um dos depoimentos prestados encontrados no Relatório do IPC analisado neste artigo, a testemunha declarou que "escutou gritos e claramente ouviu Rodrigo pedir socorro" ${ }^{20}$. Não por acaso, o título deste artigo lança mão da expressão "um bombeiro pede socorro!", o que contraria os princípios e objetivos da profissão, afeita ao epíteto de heróis para os seus profissionais acostumados a resgatar pessoas do perigo.

O que visamos foi mostrar que a violência institucional nas instituições militares, na forma de uma "pedagogia do sofrimento", faz parte da naturalização de princípios culturalmente impostos que ofuscam para seus membros (especialmente os que se encontram em posições de mando) a compreensão de que práticas como os trotes violentos, as instruções orientadas pelo sofrimento ou o assédio moral são violadoras da dignidade da pessoa humana.

Para tanto, voltamos o nosso olhar para os Corpos de Bombeiros Militares e sua cultura militarista. Primeiro, pelo fato dessas instituições constitucionalmente comporem o conjunto da Segurança Pública nacional; segundo, por quase não existirem estudos sobre a cultura interna dos bombeiros militares, porque tais profissionais possuem uma imagem positiva diante da sociedade e, por último, para compreendermos como a cultura bélica do militarismo influencia os indivíduos em instituições cuja função não é a guerra. $\mathrm{E}$, por mais que ideologicamente os bombeiros militares façam parte das instituições de Segurança Pública em nosso país, eles têm como função precípua promover a defesa civil, salvando vidas e protegendo patrimônios.

Para comprovar nosso argumento, mostramos historicamente como os bombeiros em nosso país carregam institucionalmente a perspectiva militarista desde o século XIX. Isso nos fez refletir sobre como a cultura bélica própria dos sistemas militares acompanhou o desenvolvimento dos CBMs, de modo que isto nos levou também a perceber a existência de ${ }^{20} \mathrm{O}$ depoimento encontra-se na página 25 do Relatório final do IPC. 
práticas culturais violentas nessas instituições, que adaptaram o "caldo" como forma de seguir a ideologia pedagógica militar. A partir do "caldo", o sofrimento pelo afogamento fortalece a crença de que o aluno pode obter a vitória sobre o medo, o cansaço, o fracasso em nome da virilidade, honra e coragem. Analisamos, assim, o Relatório final do IPC do caso da morte do aluno Soldado Rodrigo Claro, ocorrida em Cuiabá, em 2016. Diante dos relatos testemunhais do fato, pudemos melhor compreender a operacionalidade do "caldo" e sua relação direta com a pedagogia do sofrimento.

Por fim, fica-nos a reflexão de que a naturalização da violência institucional pelos Bombeiros Militares enseja uma crise sacrificial, ou seja, a morte de um membro reforça os valores da instituição, no momento em que prova que ser um bombeiro "não é pra qualquer um" ${ }^{21}$. Além disso, também demonstra o quanto a cultura bélica do militarismo tem a capacidade de reproduzir um ethos guerreiro capaz de levar qualquer agrupamento humano (institucional ou não) a um ideal de destruição interpretado como sucesso individual e coletivo, forjado ideologicamente pela força dos símbolos e de um espírito de solidariedade. Só que, na ausência de inimigos, restam os próprios membros do grupo para serem atingidos pelos "aguilhões" militares, os quais ditam uma cultura que teima em resistir na aprendizagem pelo sofrimento quando o assunto são instituições de caráter não bélico como as PMs e os Bombeiros Militares.

Fábio Gomes de França é Doutor em Sociologia e Professor convidado do Núcleo de Cidadania e Direitos Humanos da UFPB.

”filhosdalegiao@gmail.com

Luziana Ramalho Ribeiro é Doutora em Sociologia e Professora do Programa de PósGraduação do Núcleo de Cidadania e Direitos Humanos da UFPB.

$\risingdotseq$ luzianaribeiro.ufpb@gmail.com

${ }^{21}$ Expressão nativa geralmente utilizada por integrantes dos Corpos de Bombeiros no Brasil. Apreendemos tal informação, ao ter contato com bombeiros militares no Estado da Paraíba, especialmente alunos em formação. 


\section{Referências}

1. ALBUQUERQUE, Carlos L. de; MACHADO, Eduardo P. O currículo da selva: ensino, militarismo e ethos guerreiro nas academias brasileiras de polícia. Capítulo Criminológico, v. 29, n. 4, p. 5-33, dez. 2001 a.

2. ALBUQUERQUE, Carlos L. de; MACHADO, Eduardo P. Sob o signo de Marte: modernização, ensino e ritos da instituição policial militar. Sociologias, Porto Alegre, v. 3, n. 5, p. 214-237, jan./jun. 2001b.

3. BERTAUD, Jean-Paul. O exército e o brevê de virilidade. In: CORBIN, Alain et al. (Orgs.). História da virilidade. O triunfo da virilidade: o século XIX. Petrópolis: Vozes, 2013a. p. 74-94.

4. BERTAUD, Jean-Paul. A virilidade militar. In: CORBIN, Alain et al. (Orgs.). História da virilidade. O triunfo da virilidade: o século XIX. Petrópolis: Vozes, 2013b, p. 195-248.

5. BOURDIEU, Pierre. A dominação masculina. Rio de Janeiro: Bertrand Brasil, 2002.

6. BRASIL. Constituição (1988). Constituição da República Federativa do Brasil. Brasília: Senado Federal, 1988.

7. BRASIL. Decreto n. 8.337, de 17 de dezembro de 1881. Aprova o Regulamento reorganizando o Corpo de Bombeiros. Disponível em: https://www2.camara. leg.br/legin/fed/decret/1824-1899/decreto-8337-17-dezembro-1881-546618publicacaooriginal-60956-pe.html.

8. BRASIL. Decreto n. 9.829, de 31 de dezembro de 1887. Reforma o Corpo de Bombeiros. Disponível em: https://www2.camara.leg.br/ legin/fed/decret/1824-1899/decreto-9829-31-dezembro-1887-543355publicacaooriginal-53586-pe.html.

9. BRASIL. Decreto n. 11.497, de 23 de fevereiro de 1915. Faz a remodelação do Exercito Nacional. Disponível em: https://www2.camara.leg.br/ legin/fed/decret/1910-1919/decreto-11497-23-fevereiro-1915-513642publicacaooriginal-1-pe.html.

10. BRASIL. Lei n. 3.216, de 3 de janeiro de 1917. Fixa as forças de terra para o exercício de 1917. Disponível em: https://www2.camara.leg.br/legin/fed/lei/19101919/lei-3216-3-janeiro-1917-572527-publicacaooriginal-95671-pl.html.

11. BRASIL. Decreto-Lei n. 8.660, de 14 de janeiro de 1946. Delega aos Estados a faculdade de legislar sobre a matéria constante do no XXVI do artigo 16 da Constituição Federal (organização, instrução, justiça e garantia das forças policiais dos Estados) e dá outras providências. Disponível em: https://www2.camara. leg.br/legin/fed/declei/1940-1949/decreto-lei-8660-14-janeiro-1946-416665publicacaooriginal-1-pe.html.

12. BRASIL. Constituição (1967). Constituição da República Federativa do Brasil. Brasília: Congresso Nacional, 1967a. 
13. BRASIL. Decreto-Lei n. 317, de 13 de março de 1967. Reorganiza as polícias e os corpos de bombeiros militares dos Estados, dos Territórios e do Distrito Federal e dá outras providências. Brasília, DF, 1967b. Disponível em: http://legis. senado.gov.br/norma/523272/publicacao/15708167

14. BRASIL. Decreto-Lei n. 667, de 02 de julho de 1969. Reorganiza as Polícias Militares e os Corpos de Bombeiros Militares dos Estados, dos Território e do Distrito Federal, e dá outras providências. Disponível em: http://www.planalto. gov.br/ccivil_03/decreto-lei/Del0667.htm.

15. BRASIL. Decreto-Lei n. 1.406, de 24 de junho de 1975. Altera a redação do parágrafo único do artigo 26 do Decreto-lei no 667, de 2 de julho de 1969, que reorganiza as Polícias Militares e os Corpos de Bombeiros Militares dos Estados, dos Territórios e do Distrito Federal. Disponível em: http://www.planalto.gov.br/ ccivil_03/decreto-lei/Del1406.htm.

16. BRASIL. Decreto-Lei n. 2.010, de 12 de janeiro de 1983. Altera o Decreto-Lei no 667, de 02 de julho de 1969, que reorganiza as Polícias Militares e os Corpos de Bombeiros Militares dos Estados, dos Territórios e do Distrito Federal e dá outras providências. Brasília, DF, 1983a. Disponível em: http://www.planalto.gov. br/ccivil_03/decreto-lei/Del2010.htm.

17. BRASIL. Decreto-Lei n. 88.777, de 30 de setembro de 1983. Aprova o regulamento para as polícias militares e corpos de bombeiros militares (R-200). Brasília, DF, 1983b. Disponível em: http://www.planalto.gov.br/ccivil_03/decreto/ D88777.htm.

18. BRASIL. Lei n. 7.479, de 2 de junho de 1986. Aprova o Estatuto dos Bombeiros Militares do Corpo de Bombeiros do Distrito Federal, e dá outras providências. Diário Oficial da União. Brasília, DF, 4 jun. 1986.

19. BRASIL. Lei n. 11.901, de 12 de janeiro de 2009. Dispõe sobre a profissão de Bombeiro Civil e dá outras providências. Diário Oficial da União. Brasília, DF, 13 jan. 2009.

20. CALAZANS, Márcia E. de. Mulheres no policiamento ostensivo e a perspectiva de uma segurança cidadã. São Paulo em Perspectiva, São Paulo, v. 18, n. 1, p. 142-50, 2004.

21. CANETTI, Elias. Massa e poder. São Paulo: Companhia das Letras, 1995.

22. CASTRO, Celso. O espírito militar: um antropólogo na caserna. Rio de Janeiro: Jorge Zahar, 2004.

23. CAVALCANTI, Carlos B. Guerreiros da paz. Recife: Ed. do Autor, 2002.

24. CERQUEIRA, Homero de G. A disciplina militar em sala de aula. São Paulo: Biblioteca 24 horas, 2009.

25. COSTA, Carlos M. D'l. Os corpos de bombeiros militares emancipados das polícias militares: prospecção e análise dos parâmetros norteadores do seu "desenho" organizacional. 2002. 224 f. Dissertação (Mestrado em Administração Pública), Rio de Janeiro, Fundação Getúlio Vargas, 2002. 
26. DALABENETA, Edevaldo. A formação de soldados do corpo de bombeiros militar de Santa Catarina: análise do processo de aprendizagem, currículo e saberes docentes. 2015. 221 f. Dissertação (Mestrado em Educação), Universidade Regional de Blumenau, 2015.

27. DALABENETA, Edevaldo; SCHROEDER, Edson; CERVI, Giceli M. A formação de soldados do corpo de bombeiros militar de Santa Catarina. Pesquiseduca, Santos, v. 8, n. 16, p. 458-72, jul./dez. 2016.

28. FOUCAULT, Michel. Vigiar e punir: história das violências nas prisões. Rio de Janeiro: Vozes, 1987.

29. FOUCAULT, Michel. Um bombeiro abre o jogo. In: Ditos \& escritos VIII: segurança, penalidade e prisão. Rio de Janeiro: Forense Universitária, 2012.

30. FRANÇA, Fábio G. de. Desvio, moralidade e militarismo: um olhar sobre a formação policial militar na Paraíba. Revista Brasileira de Sociologia das Emoções, João Pessoa, v. 12, n. 36, p. 803-18, dez. 2013.

31. FRANÇA, Fábio G. de; FARIAS, Janaína L. de. "Se não aguentar, corra!": um estudo sobre a pedagogia do sofrimento em um curso policial militar. Revista Brasileira de Segurança Pública, São Paulo, v. 9, n. 2, p. 142-59, ago./set. 2015.

32. GIRARD, René. A violência e o sagrado. São Paulo: Editora Universidade Estadual Paulista, 1990.

33. GUIMARÃES. Halyny M. Núcleo interdisciplinar de educação em direitos humanos: pela construção da cultura da paz no corpo de bombeiros militar do Tocantins. 2017. 139f. Dissertação (Mestrado Profissional em Efetividade Jurisdicional em Direitos Humanos), Unniversidade Federal do Tocantins, 2017.

34. IBOPE. Confiança do brasileiro nas instituições é a mais baixa desde 2009. 2018. Disponível em: http://www.ibopeinteligencia.com/noticias-e-pesquisas/ confianca-do-brasileiro-nas-instituicoes-e-a-mais-baixa-desde-2009/.

35. KROK, Jan T. O vínculo constitucional entre o Exército e as Polícias Militares: reflexos na estrutura organizacional, formação e prática profissional (1934-1988). 2008. 118 f. Dissertação (Mestrado em História Social das Relações Políticas), Universidade Federal do Espírito Santo, 2008.

36. MATTOSO, Glauco. O calvário dos carecas: história do trote estudantil. São Paulo: EMW Editores, 1985.

37. MENEZES, José. O corpo de bombeiros no Pará. 2. Ed. Belém: Imprensa Oficial do Estado, 2007.

38. PORTAL G1. Bombeiro morre durante treinamento em Brasília. G1, 24 set. 2008. Disponível em: http://g1.globo.com/Noticias/Brasil/0,,MUL7714735598,00-BOMBEIRO+MORRE+DURANTE+TREINAMENTO+EM+BRASILIA. html.

39. PORTAL G1. Tenente bombeiro é condenado a dez anos de prisão e perde cargo, em RO. G1, 22 out. 2014. Disponível em: http://g1.globo.com/ro/rondonia/ noticia/2014/10/tenente-bombeiro-e-condenado-dez-anos-de-prisao-e-perdecargo-em-ro.html. 
40. PORTAL R7. Justiça condena bombeiros militares por provocar morte de sargento em treinamento de mergulho. R7, 28 maio 2013. Disponível em: http://noticias.r7.com/distrito-federal/justica-condena-bombeiros-militares-porprovocar-morte-de-sargento-em-treinamento-de-mergulho-28052013.

41. SENA, Getúlio N. O prescrito e o vivido na formação de oficiais militares estaduais: tensões sob a otica do currículo. 2017. 104 f. Mestrado (Dissertação em Educação, Culturas e Identidades), Universidade Federal Rural de Pernambuco, 2017.

42. SILVA, Agnaldo J. da. Praça velho: um estudo sobre o processo de socialização policial militar. 2002. Dissertação (Mestrado em Sociologia), Universidade Federal de Goiás, 2002.

43. SILVA, Sandro M. L. da. Formação dos soldados bombeiros do Estado do Pará: (re)significações das competências a partir da matriz curricular nacional de segurança pública. 2015. 100 f. Dissertação (Mestrado em Defesa Social e Mediação de Conflitos), Universidade Federal do Pará, Belém, 2015.

44. SOUZA, Marcos S. de. A violência da ordem: polícia e representações sociais. São Paulo: Annablume, 2012.

45. STORANI, Paulo. Vitória sobre a morte: a glória prometida. O "rito de passagem" na construção da identidade dos operações especiais do BOPE. 2008. 169f. Dissertação (Mestrado em Antropologia), Universidade Federal Fluminense, Niterói, 2008.

46. TOASSI, Andresa J. Heróis de fumaça: um estudo sobre os sentidos do trabalho para profissionais bombeiros. 2008. $175 \mathrm{f}$. Dissertação (Mestrado em Psicologia), Universidade Federal de Santa Catarina, Florianópolis, 2008.

47. TURNER, Victor W. O processo ritual: estrutura e antiestrutura. Petrópolis: Vozes, 2013.

48. VAN GENNEP, Arnold. Os ritos de passagem. Petrópolis: Vozes, 2011.

49. ZAVERUCHA, Jorge. A crescente inserção das forças armadas na segurança pública. In: CRUZ, Marcus V. G. da; BATITU̧CCI, Eduardo C. (Orgs.). Homicídios no Brasil. Rio de Janeiro: Editora FGV, 2007. p. 25-50.

50. ZUIN, Antônio A. S. O trote na universidade: passagens de um rito de iniciação. São Paulo: Cortez, 2002.

Recebido: 4 jul. 2018

Aceito: 11 dez. 2018 